\title{
CULTURAL IMPACT ON E-COMMERCE: A COMPARATIVE STUDY
}

\author{
Abdulah Aseri, Robert Morris University, amast35@mail.rmu.edu
}

\begin{abstract}
In 2013, e-commerce is the way of business. For efficiency, all international e-commerce communities should share the same culture but questions remain as to how individual e-commerce national communities differ. What are the similarities and differences among the e-commerce practices of different national communities? This study examined the e-commerce practices in The United States of America and The Kingdom of Saudi Arabia. The research question is: Does an e-commerce development community have a distinctive cultural identity? This is a unique study that will benefit ecommerce by further improving communication amongst global e-commerce professionals and consumers. This research could also lead to a boost in e-commerce revenue worldwide as a result of the improved communication.
\end{abstract}

Keywords: Information Technology (IT), e-commerce and culture

\section{INTRODUCTION}

According to Andam [2], e-commerce is the use of information technology to complete business transactions between businesses and businesses and individuals. E-commerce is a category that falls under the much broader term of information technology. According to Andam [2], business-to-business is ecommerce between businesses, business-to-consumer is commerce between businesses and consumers, business-to-government is commerce between businesses and government, consumer-to-consumer is commerce between consumers, and mobile commerce "is the buying and selling of goods and services through wireless technology-i.e., handheld devices such as cellular telephones and personal digital assistants (PDAs)" [2].

\section{Cultural Impact on e-commerce}

Societal culture, as discussed by Hofstede [11], refers to a set of shared values, beliefs, assumptions and practices that shape and guide members' attitudes and behavior in the society. According to Hofstede [12], culture is defined "as the collective programming of the mind that distinguishes the members of one group or category of people from another." Information technology developed in one country or culture cannot be simply translated into another culture. For this reason, culture is viewed as a significant factor that affects the adoption of information technology [7]. It is apparent that every culture has developed with its own history, language, and religions creating identities that have been influenced by very different experiences. These experiences clearly affect a country's perspective on the world. Culture has an effect on the country's response to diverse events including the adoption of information technology [3]. Cultures have shown a definite effect on information technology adoption. It can effect whether an entire information technology development is completely rejected by a nation or if it is partially accepted with the rejection of certain features of the technology [17]. Culture, religion and language are significant issues in internet technology adoption in any country [14].

\section{Hofstede's Cultural Dimensions}

After conducting research in over fifty (50) countries, Hofstede [10] developed his cultural dimensions model including the following dimensions:

1. Power Distance Index

2. Collectivism versus Individualism

3. Masculinity versus Femininity

4. Uncertainty Avoidance Index 


\section{Issues in Information Systems \\ Volume 14, Issue 1, pp.431-440, 2013}

\section{Long-term versus Short-term Orientation}

Hofstede's research included surveys of IBM employees. The five dimensions were found to be valid and reliable. Individualism-collectivism refers to the basic level of behavior regulation, whether by individuals or groups. People high on individualism view self and immediate family as relatively more important than the collective. Masculine cultures emphasize work and material accomplishments; feminine societies put human relationships at the forefront. Power distance represents the extent of adherence to formal authority channels and is the degree to which the lesser powerful accept the prevailing distribution of power. High power distance cultures have members who are much more comfortable with centralized power than members of low power distance cultures. Uncertainty avoidance refers to how much people feel threatened by ambiguity, as well as the felt importance of rules and standards. People with an orientation low on uncertainty avoidance prefer situations that are free and not bound by rules and regulations. Short-term vs. long-term orientation is people's basic reference period; Short-term involves the tendency toward consumption and maintaining materialistic status, and long-term suggest thrift, perseverance, following tradition, and deferred satisfaction $[5,13]$.

The results from Hofstede's original study were:

USA - PDI: 40; IDV: 91; MAS: 62; UAI: 46; LTO: 29

KSA - PDI: 95; IDV: 25; MAS: 60; UAI: 80; LTO: no data

According to Cateora, Gilly and Graham [4], those cultures that score high in individualism(IDV), low in uncertainty avoidance(UAI) and low in power distance index(PDI) tend to be innovative and more likely to accept new innovations. The culture of The United States of America demonstrates these qualities with an IDV of 91, UAI of 46 and PDI of 40. The culture of The Kingdom of Saudi Arabia demonstrates the opposite qualities with an IDV of 25, UAI of 80 and PDI of 95.

\section{E-commerce in The Kingdom of Saudi Arabia}

In a report conducted by Sacha Orloff Consulting Group [15], e-commerce in The Kingdom of Saudi Arabia was explored. They found that, "The adoption and diffusion of the e-commerce model in Saudi Arabia has mainly been hampered by specific socio-cultural business traits which inhibit the risk-taking characteristics of enterprises." The largest barriers were noted to be payment systems, banking transaction difficulties, P.O. Box address system and speed and access to the internet. However, one significant driver to the adoption of e-commerce is that The Kingdom of Saudi Arabia had the most significant retail market in the GCC countries. Many international brands have also done business in The Kingdom of Saudi Arabia. The Kingdom of Saudi Arabia's youth population has also been eager for more technology. The country also held the greatest mobile market in the region. Sacha Orloff Consulting Group [15] found that "With $95 \%$ of the population owning a mobile, mobile internet penetration has grown to $54 \%$ with $70 \%$ mobile internet usage rates" (p. 9). Another finding was that, "Saudi Arabia has the largest and fastest growth of Information and Communication Technology (ICT) market place in the Arab region." The Kingdom of Saudi Arabia's collectivist society tends to inhibit consumer trust in e-commerce. A case study about United Electronics Company eXtra was also included in this report. This company had great retail success. eXtra launched its website in July 2011. This makes eXtra the only company of its kind that conducted e-commerce for 23 cities and provided home delivery. With its retail success to back it up, eXtra has significant potential for e-commerce success.

Eskander and Abdul Aal [1] conducted a study to determine if IKEA's culture could fit in to The Kingdom of Saudi Arabia's culture. The study was conducted through interviews and observations. IKEA chose Ghassan Ahmed Al Sulaiman as its franchise owner. He was a well known businessman in The Kingdom of Saudi Arabia. This did much to gain consumer trust in this collectivist society. Its first store was only 800 square meters. IKEA now has three stores in The Kingdom of Saudi Arabia. Two of these stores are 28,000 square meters and one is 22,000 square meters. One of the most important factors to IKEA's success in The Kingdom of Saudi Arabia was the franchise owner that was chosen. Since he was well known, business would definitely be brought in. There were other factors that contributed to IKEA's 


\section{Issues in Information Systems \\ Volume 14, Issue 1, pp.431-440, 2013}

success in The Kingdom of Saudi Arabia. These factors included adaptations made by IKEA in consideration of the culture of The Kingdom of Saudi Arabia. The following adaptations were made:

1. The uniform was modified.

2. Products are conservative rather than western.

3. There is partial self-service rather than full self-service.

4. Festivals celebrated are Islamic festivals and IKEA new year rather than Swedish festivals.

5. There is gender separation.

6. There is a fairly open culture rather than a liberal one.

7. Pork and alcohol were removed from the restaurant menu.

8. Shawerma was added to the restaurant menu.

9. Products were to include no other religious symbols other than Islamic and were to include two languages.

10. A prayer room was added to the store and is not to play music.

11. No women were to appear in the catalogue.

Since IKEA adapted to the Saudi culture rather than trying to change it they have been a grand success. These adaptations certainly align with The Kingdom of Saudi Arabia's high power distance index, low individualism and high uncertainty avoidance index. I do not feel IKEA would have succeeded without these compromises. [1]

\section{E-commerce in The United States of America}

Fomin, King, Lyytinen \&McGann [8] found that:

1. USA businesses have taken the lead in email usage and file sharing services

2. It is also noted that businesses maintained a high percentage of internet connection, website establishment and email usage

3. USA businesses lead other countries in on-line sales (17.6\%) for business-to-business (B2B) and business-to-consumer (B2C) combined.

According to the U.S. Census Bureau [16], manufacturers led in e-commerce sales at $42 \%$ of total manufacturing shipments. Merchant wholesales followed at $23.4 \%$ of total sales. In the retail sector, esales accounted for $40 \%$ of total retail sales. The majority of these sales fell under the nonstore retailers and motor vehicles and parts dealers groups. Nonstore retailers refers to electronic shopping and mail order.

Cultural traits were important to consider when marketing or creating a web design for any business looking to expand to another country. This was found to be especially true in the study conducted by Lo and Gong [9] which examined the differences in e-commerce websites between The United States of America and China. Fifty e-commerce websites were reviewed from each country. They specifically focused on the impact of culture on the websites' color usage, page layout, site content and interactivity. It was found that the U.S. used the highest amount of blue followed by white, black and yellow whereas China used the highest amount of blue followed by red, yellow and black. Culture played a role for China because red symbolizes good luck, wealth and marriage but white represents death and mourning. Active banners and animations were found to be higher in the page layouts of the Chinese websites whereas the U.S. used more white space and icons. They found that the page layouts can be attributed to China's high uncertainty avoidance index and a tactic to create trust. These sites also utilized this layout to bring more visitors to their sites to allow trust to be established through its culture's collectivist nature.

\section{RESEARCH METHODOLOGY}

The purpose of this study was to determine if the e-commerce communities of the businesses in The United States of America and The Kingdom of Saudi Arabia have a distinctive cultural identity. The research question is: Does an e-commerce development community have a distinctive cultural identity? There are two sub questions for this study: Is this community limited to e-commerce, the country, the audience? and 


\section{Issues in Information Systems \\ Volume 14, Issue 1, pp.431-440, 2013}

Is this community subject to demographic situations?. I utilized Hofstede's Cultural Dimensions Model as the framework for understanding the differences in the cultural dimensions. The cultural dimensions are: Power Distance Index (PDI), Individualism (IDV), Masculinity (MAS), Uncertainty Avoidance (UAI), and Long-Term Orientation (LTO). This model of studying culture was found to be reliable and valid since its original study in 1980. Hofstede's Cultural Dimensions model was ultimately chosen because of its reliability along with its ease of use in consideration of time constraints.

I made use of surveys and interviews to perform data collection for this mixed methodology study. The mixed methods approach was chosen to allow for both the comparison of cultural traits between national cultural values and e-commerce development community cultural values as well as to get further insight into the current state of e-commerce in each country. The Values Survey Module provided information about the cultural values of the participants and the interview was designed to gather information specifically about the participants' e-commerce practices. For the survey portion, I utilized the Values Survey Module questionnaire (VSM) that was used by Hofstede. This questionnaire allowed for the analysis of cultures to determine their values. The VSM numerically measured cultural values to determine the results using the formulas found in the VSM 94 manual. Survey participants were either emailed the survey or asked to complete the survey on www.surveymonkey.com. The follow-up interview portion of the data collection included the following questions:

1. In what other countries, if any, do you conduct e-commerce?

2. What products and/or services does your e-commerce provide?

3. What factors do you consider in an e-commerce web design locally, regionally, and globally? Why?

4. When designing your website did you follow previously formatted website designs used locally or did you customize a unique design?

5. Are you affiliated with any other e-commerce? If so, are they located locally, regionally or globally?

6. What, if any, improvements do you feel your e-commerce can make to increase customer satisfaction?

7. What factors have contributed to your success in the local, regional and/or global markets?

Two individuals from each county that had completed the survey portion of this study were interviewed. Interviews were conducted via Skype or telephone. The interview questions were analyzed utilizing Creswell's [6] approach to interview data analysis. I searched for themes to the responses in order to map the interview responses back to the literature review to determine if there was a theme of cultural identity between the countries being studied as well as a theme related to the state of e-commerce in each country.

The participants for this study were e-commerce professionals in the e-businesses of The United States of America and The Kingdom of Saudi Arabia. An e-commerce professional was defined as any person who is charged with the purchasing and selling of products and/or services online for a business. These countries were chosen in order to evaluate if the results of the study are consistent among different cultures. More specifically, The United States of America was chosen due to its status as the biggest market in the world and The Kingdom of Saudi Arabia was chosen due to its status as the major player in the Middle East as well as its persistence to become a greater competitor to advanced countries in the field of ecommerce. I utilized a convenience sample to acquire data and snowballing to obtain more participants. The sample size of 33 participants per country was found to be sufficient because the cultural values of a very specific subset of each culture was being studied and compared to the larger national cultural values calculated by Hofstede that serve the purpose as the baseline dataset.

\section{RESULTS}

The formula developed to determine a country's PDI score was: PDI $=-35 \mathrm{~m}(03)+35 \mathrm{~m}(06)+25 \mathrm{~m}(14)-$ $20 \mathrm{~m}(17)-20$ in which $\mathrm{m}(03), \mathrm{m}(06), \mathrm{m}(14)$ and $\mathrm{m}(17)$ stands for the mean values of questions $3,6,14$, and 17 of the VSM 94 survey. The range of the index was from 0 for a low power distance index to 100 for a high power distance index. The USA was found to have a PDI score of 40.25 while KSA was found to have a PDI score of 38.65 .

The formula developed to determine a country's IDV score was: IDV $=-50 \mathrm{~m}(01)+30 \mathrm{~m}(02)+20 \mathrm{~m}(04)-$ $25 \mathrm{~m}(08)+130$ in which $\mathrm{m}(01), \mathrm{m}(02), \mathrm{m}(04)$, and $\mathrm{m}(08)$ stands for the mean values of questions $1,2,4$, 


\section{Issues in Information Systems \\ Volume 14, Issue 1, pp.431-440, 2013}

and 8 of the VSM 94 survey. The range of the individualism scores was from 0 to 100 . A low score represented a collectivist society and a high score represented an individualist society. The USA was found to have an IDV score of 72.5 while KSA was found to have an IDV score of 70.25 .

The formula developed to determine a country's MAS score was: MAS $=+60 \mathrm{~m}(05)-20 \mathrm{~m}(07)+20 \mathrm{~m}(15)$ $-70 \mathrm{~m}(20)+100$ in which $\mathrm{m}(05), \mathrm{m}(07), \mathrm{m}(15)$, and $\mathrm{m}(20)$ stood for the mean values of questions $5,7,15$, and 20 of the VSM 94 survey. The range of the masculinity scores was from 0 to 100 . A low score represented a feminine society and a high score represented a masculine society. The USA was found to have an MAS score of 48 while KSA was found to have an MAS score of 70.4 .

The formula developed to determine a country's UAI score was: UAI $=+25 \mathrm{~m}(13)+20 \mathrm{~m}(16)-50 \mathrm{~m}(18)-$ $15 \mathrm{~m}(19)+120$ in which $\mathrm{m}(13), \mathrm{m}(16), \mathrm{m}(18)$, and $\mathrm{m}(19)$ stood for the mean values of questions $13,16,18$, and 19 of the VSM 94 survey. The range of the uncertainty avoidance index scores was from 0 to 100 . A low score represented a low degree of uncertainty avoidance and a high score represented a high degree of uncertainty avoidance. The USA was found to have a UAI score of 83.10 while KSA was found to have a UAI score of 33.7 .

The formula developed to determine a country's LTO score was: LTO $=-20 \mathrm{~m}(10)+20 \mathrm{~m}(12)+40$ in which $\mathrm{m}(10)$ and $\mathrm{m}(12)$ stands for the mean values of questions 10 and 12 of the VSM 94 survey. The range of the Long-term orientation scores was from 0 to 100. A low score represented a society that is short-term oriented and a high score represented a society that is long-term oriented. The USA was found to have an LTO score of 42.2 while KSA was found to have an LTO score of 52.2.

After collecting demographic data and cultural dimension data I tested for a relationship between some of the demographics and cultural factors. The cultural factors that were believed to be the most significant in determining if the e-commerce development community had its own identity included the power distance index and uncertainty avoidance index. Both of these factors have been linked to information technology developments. Tables $1-3$ show the distribution of age, education and gender.

Table 1. Age

\begin{tabular}{|l|l|l|}
\hline Age & USA & KSA \\
\hline Under 20 & 0 & 2 \\
\hline $20-24$ & 3 & 7 \\
\hline $25-29$ & 4 & 13 \\
\hline $30-34$ & 4 & 8 \\
\hline $35-39$ & 2 & 2 \\
\hline $40-49$ & 15 & 1 \\
\hline $50-59$ & 5 & 0 \\
\hline Over 60 & 0 & 0 \\
\hline
\end{tabular}

Table 2. Education

\begin{tabular}{|l|l|l|}
\hline Years of Education & USA & KSA \\
\hline 10 or less & 0 & 4 \\
\hline 12 & 5 & 9 \\
\hline 13 & 0 & 3 \\
\hline 14 & 4 & 3 \\
\hline 15 & 1 & 1 \\
\hline 16 & 3 & 1 \\
\hline 17 & 2 & 1 \\
\hline 18 or more & 18 & 11 \\
\hline
\end{tabular}

Table 3. Gender

\begin{tabular}{|l|l|l|}
\hline Gender & USA & KSA \\
\hline
\end{tabular}




\section{Issues in Information Systems}

Volume 14, Issue 1, pp.431-440, 2013

\begin{tabular}{|l|l|l|}
\hline Female & $48.48 \%$ & $24.24 \%$ \\
\hline Male & $51.52 \%$ & $75.76 \%$ \\
\hline
\end{tabular}

I used the Pearson's correlation to test for a relationship between power distance index and age for the American participants. The result, $\mathrm{r}=0.82, \mathrm{n}=33$, suggested a significant linear relationship between age and power distance. This means that the older American participants had a higher power distance index than the younger participants.

The Pearson's correlation was repeated to test the relationship between uncertainty avoidance index and age for the American participants. The result, $\mathrm{r}=0.83, \mathrm{n}=33$, suggested a significant linear relationship between uncertainty avoidance and age. This means that the older American participants had a higher uncertainty avoidance index than the younger participants.

The relationship between education and power distance index for American participants was also tested using the Pearson's correlation. The result, $\mathrm{r}=0.72, \mathrm{n}=33$, suggested a significant linear relationship between education and power distance index. This means that the more educated American participants had a higher power distance index than the less educated American participants.

The Pearson's correlation was again used to test the relationship between education and uncertainty avoidance index for American participants. The result, $\mathrm{r}=0.51, \mathrm{n}=33$, suggested a moderate linear relationship between education and uncertainty avoidance. This means that a fair amount of the more educated American participants had a higher uncertainty avoidance index than the less educated American participants.

The Pearson's correlation was also performed to test the relationship between age and power distance index for the Saudi Arabian participants. The result, $\mathrm{r}=0.39, \mathrm{n}=33$, suggested a moderate correlation between age and power distance index. This means that a fair amount of the older Saudi Arabian participants had a higher power distance index than the younger Saudi Arabian participants.

The relationship between age and uncertainty avoidance for the Saudi Arabian participants was also tested using the Pearson's correlation. The result, $\mathrm{r}=0.99, \mathrm{n}=33$, suggested a significant linear relationship between age and uncertainty avoidance. This means that the older Saudi Arabian participants had a higher uncertainty avoidance index than the younger Saudi Arabian participants.

Pearson's correlation was also used to test the relationship between education and power distance index for the Saudi Arabian participants. The result, $\mathrm{r}=0.02, \mathrm{n}=33$, suggested that there is no correlation between education and power distance index.

The relationship between education and uncertainty avoidance index for the Saudi Arabian participants was also tested using the Pearson's correlation. The result, $\mathrm{r}=0.53, \mathrm{n}=33$, suggested a moderate linear relationship between education and uncertainty avoidance. This means that a fair amount of the more educated Saudi Arabian participants had a higher uncertainty avoidance index than the less educated Saudi Arabian participants.

\section{Interview}

Two American and two Saudi Arabian participants were interviewed. In order to analyze this data, Creswell's [6] approach to finding themes within interviews was used. Since there were only five variables including global, local, affiliations, improvements needed and factors contributing to success, it was determined that data analysis software would not be needed for this study. Table 4 demonstrates the themes of the interview results from the American and Saudi Arabian interview participants. 


\section{Issues in Information Systems}

Volume 14, Issue 1, pp.431-440, 2013

Table 4.Themes of Interview Results

\begin{tabular}{|l|l|l|}
\hline QUESTION & USA & KSA \\
\hline 1 & Global & Local \\
\hline 2 & Global & Local \\
\hline 3 & Global & local \\
\hline 4 & Global & Local \\
\hline 5 & Has affiliations & No affiliations or local affiliations \\
\hline 6 & Strong emphasis on improving customer & Strong emphasis on improving \\
& satisfaction & customer satisfaction \\
\hline 7 & Product quality and customer satisfaction & Advertising via television and \\
& & social networking \\
\hline
\end{tabular}

\section{CONCLUSIONS}

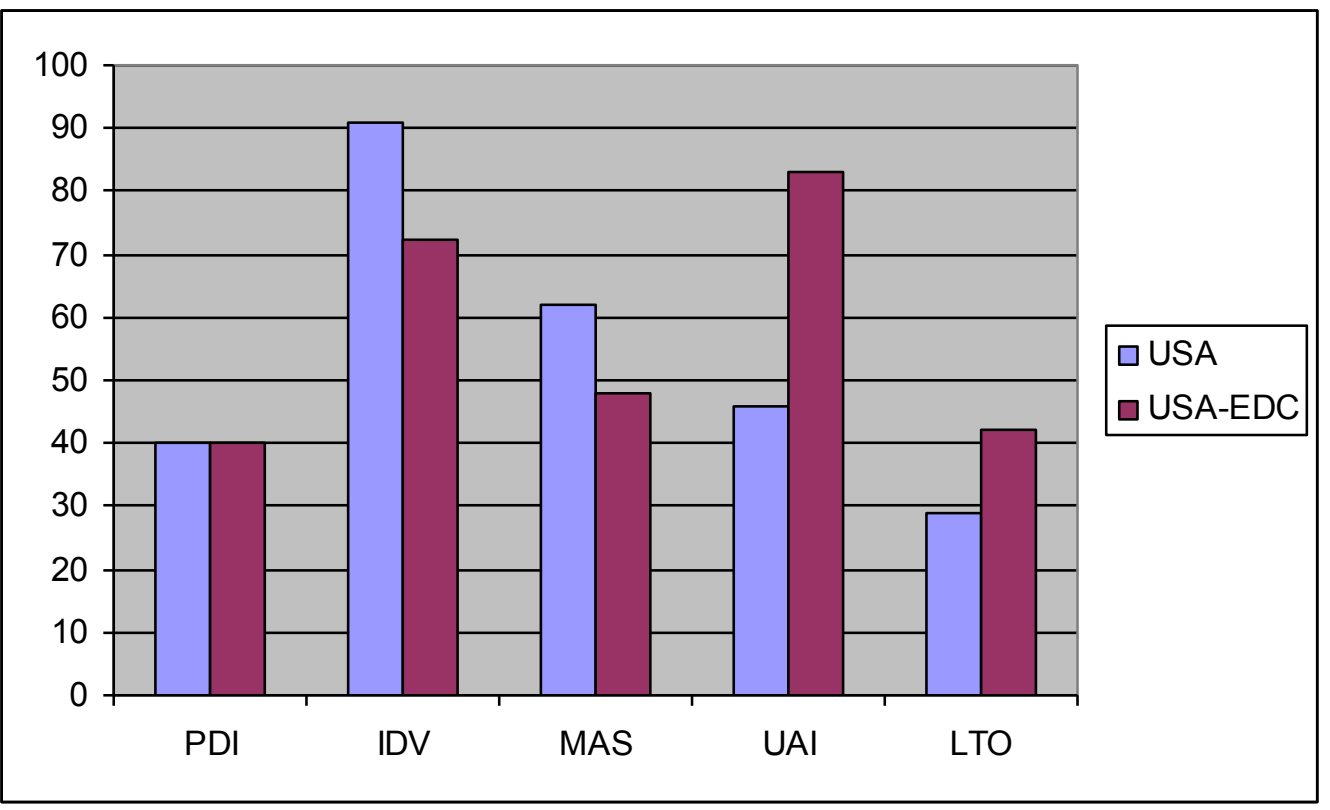

Figure 1 demonstrates the comparison of the cultural dimension scores between USA and USA-Ecommerce Development Community (EDC).

As seen in Figure 1, PDI remained the same while slight differences were shown in IDV, MAS, and LTO. The largest difference was found in UAI. The e-commerce development community scored 83.10 in the uncertainty avoidance index. Through the use of Pearson's correlation, strong linear relationships were found between age and PDI as well as age and UAI. The largest portion of the survey participants were in the age category $40-49$ and accounted for $45.45 \%$ of the total survey participants. The next age group, 5059 accounted for $15.15 \%$ of the total survey participants. Together the age group $40-59$ accounted for $60.6 \%$ of the total survey participants. A significant linear relationship was found between education and 


\section{Issues in Information Systems \\ Volume 14, Issue 1, pp.431-440, 2013}

PDI while a moderate linear relationship was found between education and UAI. The highest educated interview participants accounted for $54.55 \%$ of the total interview participants.

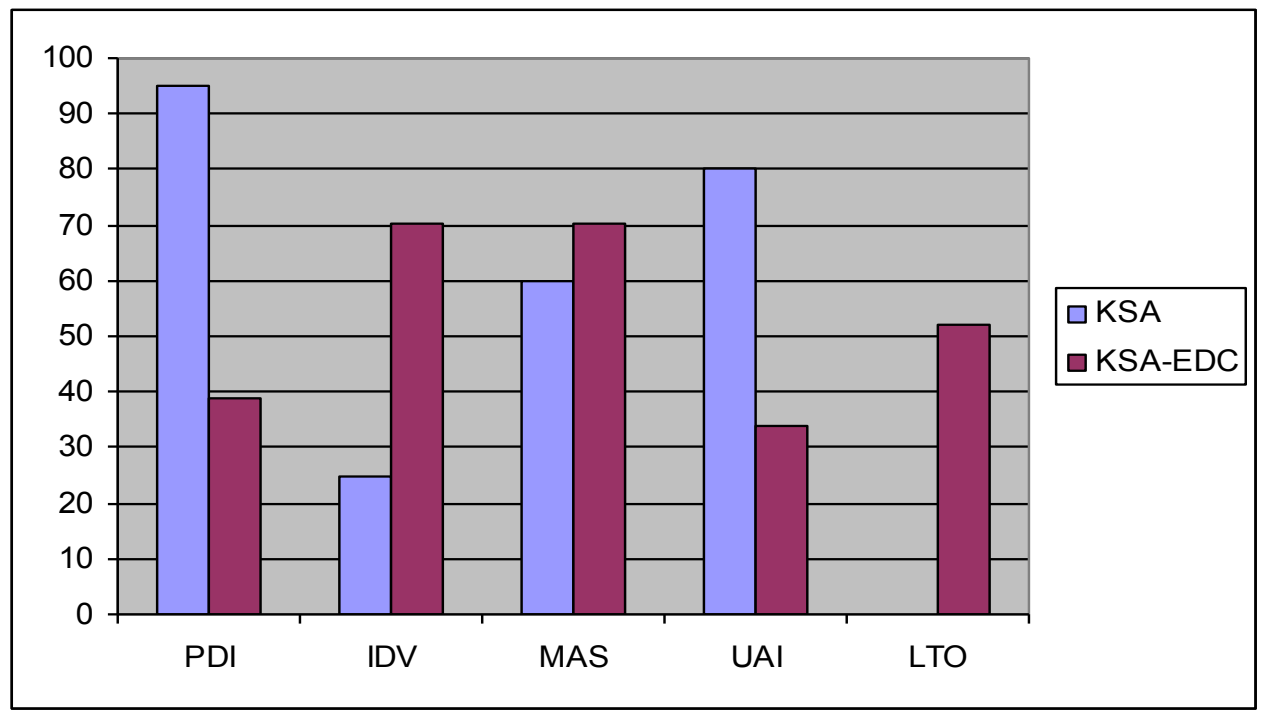

Figure 2 demonstrates the comparison of the cultural dimension scores between KSA and KSA-Ecommerce Development Community (EDC).

As seen in Figure 2, PDI, IDV and UAI showed the most significant differences, while MAS showed a slight difference and LTO could not be measured since original data does not exist. Through the use of Pearson's correlation, a moderate linear relationship was found between age and PDI, while a strong linear relationship was found between age and UAI. The largest portion of Saudi Arabian participants were in the age group $25-29$ at $39.39 \%$, while there were no participants that were 60 or over and only $3.03 \%$ in the age group 40-59. No relationship was found between education and PDI, while a moderate linear relationship was found between education and UAI. The largest portion of survey participants were at the education level of 18 years and over at $30.3 \%$ of total participants. The next largest portion of survey participants was at the education level of 17 years at $18.18 \%$.

The interviews were themed by global and local characteristics as well as affiliations, improvements needed and factors contributing to success. The USA interviewees were found to demonstrate global characteristics in their responses to question 1. In question 2, the USA interviewees also demonstrated global characteristics. Again in question 3, global traits were found. Question 4 also showed global qualities, Question 5 demonstrated that affiliations existed with other e-commerce. Question 6 showed a strong emphasis on improving customer satisfaction. Question 7 demonstrated that product quality and customer satisfaction were the two most important factors that contributed to the success of the ecommerce.

The KSA interviewees were found to demonstrate local characteristics in their responses to question 1. Question 2 also showed local traits. Again, in question 3, local characteristics were found. Local qualities were also found in question 4. In question 5, the KSA interviewees were found to either have no affiliations or only local affiliations. A strong emphasis on improving customer satisfaction was found in question 6 responses. Advertising via television and social networking were found to be the driving factors behind the success of the e-commerce businesses of the interviewees in question 7.

In the results from the VSM94 Values Survey Module for both the USA and KSA differences were found between the culture's baseline dimension scores and the e-commerce development community's dimension scores. The USA participants demonstrated differences in four of the five dimensions but most notably in the uncertainty avoidance index. Though there was a much larger population of older participants from the USA, the interviews definitely demonstrated a global attitude indicating the e-commerce development 


\section{Issues in Information Systems \\ Volume 14, Issue 1, pp.431-440, 2013}

community in the USA has its own identity. The KSA participants demonstrated differences in four of the five dimensions with particularly high differences in the power distance index and uncertainty avoidance index. Though the majority of the survey participants were younger in age, this is the age group that accounts for the majority of the e-commerce development community members in KSA. The older population in KSA has very few members in the e-commerce development community. The interview results demonstrated a local attitude with a desire to expand to the global market. These results put together with the cultural dimension scores demonstrate that the e-commerce development community in KSA has its own identity.

Though it can be said that the e-commerce development community members of each country has their own identity, it can not be said that these results apply globally. Both the USA and KSA demonstrated differences from their national culture in both dimension scores and interview responses. However, the dimension scores and interview responses were not the same for the e-commerce development community of both countries when compared.

\section{Limitations of research}

The limitations of research for this study include:

- The sample size presented a limitation in that a large sample would certainly allow for a better picture of the e-commerce development communities in each country.

- There were only two interviewees for each country. This also could have limited the study to a very small set of responses.

- This study was also limited by the survey version chosen in anticipation of utilizing the CultureGPS application. Since the CultureGPS application focused on the first five dimensions only, it was determined that the VSM94 survey should be used and that the data would be manually entered into the CultureGPS software. Unfortunately, this application contained completely different questions and could not be utilized in the study.

- Hofstede's original results for KSA were calculated by including KSA in a set of countries labeled the Arab speaking countries. KSA was the least represented in this group and all Arab speaking countries do not have the same cultural characteristics [11].

\section{Further research and recommendations}

- It is recommended that more countries be added to this study to further clarify any similarities among the dimension index scores internationally. Since the study only focused on two different countries, there is much to be discovered in regards to e-commerce development communities.

- It is also recommended that the researcher complete each country's baseline surveys in order to establish the most up to date information for each culture. Since there was no existing baseline data for the long-term orientation dimension for The Kingdom of Saudi Arabia, a comparison could not be completed. Gathering of the researchers own baseline data would eliminate this problem

- It is also suggested that further research be conducted utilizing the VSM08 survey to determine if other dimensions added to this newer version of the survey apply to this subject. This would provide more information to compare the results in determining the e-commerce development community's identity.

\section{REFERENCES}

1. Abdul Aal, M.K. and Eskander, D. (2010). Does IKEA Culture Apply Abroad? A Study of IKEA in Saudi Arabia. Retrieved from: http://kau.divaportal.org/smash/record.jsf?pid=diva2:403657

2. Andam, Z. (2003). e-Commerce and e-business. e-ASEAN Task Force UNDP- APDIP. Retrieved from: http://www.apdip.net/publications/iespprimers/eprimer-ecom.pdf

3. Boyacigiller, N. \& Adler, N. (1991) The Parochial Dinosaur: The Organizational Sciences in a

Global Context. Academy of Management Review, 16(2), 262-291.

4. Cateora, P.R., Gilly, M.C. and Graham, J.L. (2008). International Marketing. McGraw-Hill.

5. Chai, L. \& Pavlou, P. (2002). What drives electronic commerce across cultures? A cross-cultural empirical investigation of the theory of planned behavior. Journal of Electronic Commerce Research, 3(4), 240-253. 


\section{Issues in Information Systems}

Volume 14, Issue 1, pp.431-440, 2013

6. Creswell, J.W. (2007). Qualitative Inquiry \& Research Design: Choosing Among Five

Approaches. Thousand Oaks, CA: Sage Publications, Inc.

7. Fey, C., \& Denison, D. (2003). Organizational Culture and Effectiveness: Can American Theory

Be $\quad$ Applied in Russia? Organization Science.

8. Fomin, V. V., King, J. L., Lyytinen, K. J., McGann, S. T. (2005). Diffusion and impacts of ecommerce in the United States of America: Results from and industry survey. Communications of the Association for Information Systems, 16, 559-603.

9. Gong, P. and Lo, B.W.N. (2005). Cultural Impact on the Design of E-commerce Websites: Part ISite Format and Layout. Issues in Information Systems, VI(2), 182-188.

10. Hofstede, G. (1980). Culture's consequences: International differences in work related values.

Beverly Hill, CA, Sage.

11. Hofstede, G. J. (1991). Cultures and Organizations, Software of the Mind. London: McGraw-Hill.

12. Hofstede, G. J. (2001). Culture's consequences: comparing values, behaviors, institutions, and organizations across nations $\left(2^{\text {nd }}\right.$ ed.). Thousand Oaks, CA: Sage Publications.

13. Hofstede, G.J. (2010). Culture's and Organizations: Software of the Mind: Intercultural Cooperation and Its Importance for Survival. ( $3^{\text {rd }}$ ed.). McGraw-Hill.

14. Press, L., Burkhart, G., Foster, W., \& Goodman, S. (1998). An Internet diffusion framework. Communications of the ACM, 41, 21-26.

15. Sacha Orloff Consulting Group. (2012). E-commerce in Saudi Arabia: Driving the evolution, adaption and growth of e-commerce in the retail industry. Retrieved from:

http://static.wamda.com/web/uploads/resources/E-Commerce_in_Saudi_Arabia_Driving_The Evolution_Adaptation_and_Growth_of_ecommerce_in_the_Retail_Industry_SOCG_2012June 17. pdf

16. U.S. Census Bureau. (2011). E-Stats: E-commerce 2009. Retrieved from http://www.census.gov/econ/estats/2009/2009reportfinal.pdf

17. Watson, T., Teck, H., \& Raman, K. (October 1994). Culture: A Fourth Dimension of Group Support Systems. Communications of The ACM, 45-55 